\title{
Health system strengthening for mental health in low- and middle-income countries: introduction to the Emerald programme
}

\author{
Graham Thornicroft and Maya Semrau
}

\section{Summary}

This paper gives an overview of the Emerald (Emerging mental health systems in low- and middle-income countries) programme and introduces the subsequent seven papers in this BJPsych Open thematic series. The aims of the Emerald research programme were to improve mental health outcomes in six lowand middle-income countries (LMICS), namely Ethiopia, India, Nepal, Nigeria, South Africa and Uganda, by building capacity and by generating evidence to enhance health system strengthening in these six countries. The longer-term aim is to improve mental healthcare, and so contribute to a reduction in the large treatment gap that exists for mental disorders. This series includes papers describing the following components of the Emerald programme: (a) capacity building; (b) mental health financing; (c) integrated care (d) mental health information systems; and (e) knowledge transfer. We also include a cross-cutting paper with recommendations from the Emerald programme as a whole. The inclusion of clear mental-health-related targets and indicators within the United Nations Sustainable Development Goals now intensifies the need for strong evidence about both how to provide effective treatments, and how to deliver these treatments within robust health systems.

\section{Declaration of interest}

None.

\section{Keywords}

Global mental health; health systems; health system strengthening; healthcare delivery.

\section{Copyright and usage}

(C) The Royal College of Psychiatrists 2019. This is an Open Access article, distributed under the terms of the Creative Commons Attribution-NonCommercial-NoDerivatives licence (http://creativecommons.org/licenses/by-nc-nd/4.0/), which permits noncommercial re-use, distribution, and reproduction in any medium, provided the original work is unaltered and is properly cited. The written permission of Cambridge University Press must be obtained for commercial re-use or in order to create a derivative work.

\section{Background}

This thematic series in BJPsych Open reports on the work and findings of the Emerald (Emerging mental health systems in low- and middleincome countries) programme. ${ }^{1}$ Emerald was funded over 5 years (2012-2017) by the European Union's 7th framework programme to support health system strengthening research related to mental health. In this context a health system is defined as 'the sum total of all the organizations, institutions and resources whose primary purpose is to improve health" ${ }^{2}$ within which the World Health Organization (WHO) has identified six core system components (see Fig. 1)

\section{The challenge}

At present, health systems fail people with mental disorders in every country worldwide. At best only a third of people with mental disorders are treated in some high-income countries, and at worst fewer than $5 \%$ of people with mental disorders in low- and middle-income countries (LMICs) receive any treatment or care. $^{3-6}$ This large disparity between true levels of need and actual treatment rates is referred to as the 'treatment gap'. This gap is due, in part, to the substantial under-resourcing for mental health, which results in far too few human resources for mental health and a reliance on a small number of beds in tertiary hospitals. Stigma and discrimination may also contribute to the treatment gap because people do not access services or are exposed to human rights abuses. The gap exists even though the substantial contribution of mental disorders to the global burden of disease is increasingly recognised, ${ }^{7,8}$ as well as their cross-cultural applicability and relevance to sustainable development. ${ }^{9,10}$ Although there are now several high-quality sources that synthesise information on effective

interventions for people with mental disorders, ${ }^{11-13}$ far less developed is our understanding of what elements must be put in place at the national, regional and community levels to support the long-term delivery of effective mental health services. ${ }^{14,15}$

The aims of the Emerald programme were to improve mental health outcomes in six LMICs (Ethiopia, India, Nepal, Nigeria, South Africa and Uganda) by building capacity and by generating evidence to enhance health system strengthening, thereby improving mental healthcare and so contributing to a reduction in the mental health treatment gap. The key characteristics of the six Emerald country sites are shown in Table 1. These countries all face the formidable mental health system challenges that are common across LMICs, such as weak governance, a low resource base and poor information systems. The six countries were invited into the programme as a result of the commitment of local researchers and policymakers to engage in this programme, and to provide a rich comparison of sites in relation to their geographical, economic, sociocultural and urban/rural contexts, in order to strengthen the generalisability of the findings.

\section{The five components of the Emerald programme}

The Emerald programme entailed the coordination of the following five components (called work packages).

\section{Capacity building}

This work by Sara Evans-Lacko, Charlotte Hanlon, Atalay Alem and colleagues is described in paper two of this BJPsych Open thematic series, ${ }^{18}$ which builds upon previous reports. ${ }^{19-26}$ The Emerald programme has successfully supported the doctoral $(\mathrm{PhD})$ studies of ten students across the six LMICs (three from Ethiopia, two from India, one from Nepal, one from Nigeria, two from South Africa, one from the UK). In addition, three Masters-level teaching 
System building blocks

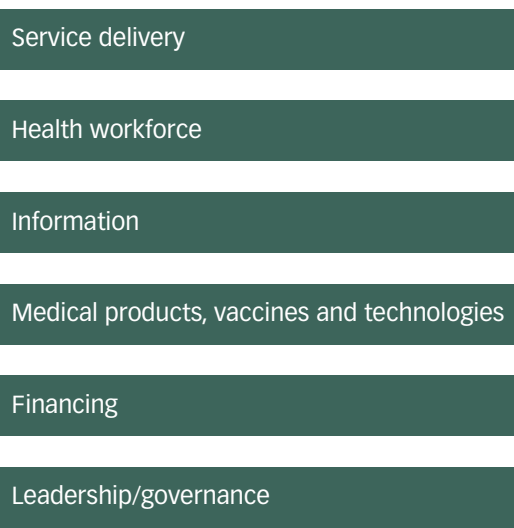

Overall goals/outcomes

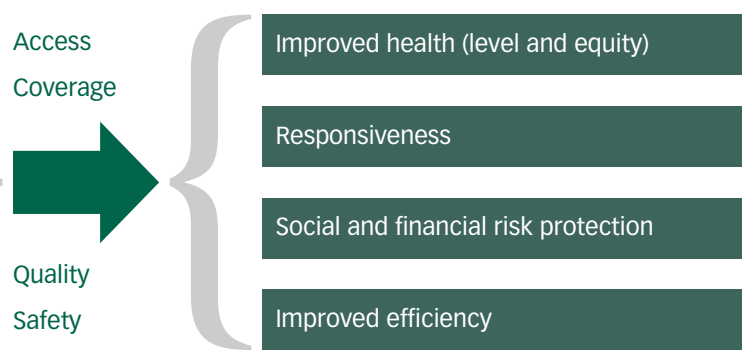

Fig. 1 The World Health Organization (WHO) health system framework (figure); page 3, 2007. Everybody's Business - Strengthening Health Systems to Improve Health Outcomes: WHO's Framework for Action.

modules with 28 submodules (see Appendix) have been developed that can be integrated into ongoing Masters courses, as well as three short courses for: (a) researchers; (b) policymakers and planners; and (c) patients and caregivers, to build capacity in mental health systems research within Emerald countries and beyond. These training materials are available for open access to relevant staff in countries worldwide using a Creative Commons licence.

\section{Mental health financing}

Paper three in this BJPsych Open thematic series considers strategies for sustainable mental health system financing in LMICs, ${ }^{27}$ led by Dan Chisholm, Crick Lund and Sumaiyah Docrat. ${ }^{28-30}$

\section{Integrated care}

Within Emerald, we have deliberately approached the scaling up of services to identify and treat many more people with mental disorders in LMICs by integrating these activities into mainstream primary and community healthcare services. Paper four in this series $^{31}$ is coordinated by Inge Petersen and Fred Kigozi, and discusses the key barriers and facilitators related to such integrated care. ${ }^{14,32-36}$

\section{Mental health information systems}

Knowledge of how health systems perform, in order to manage and improve them, is crucial yet such data are most often missing, scarce

\begin{tabular}{|c|c|c|c|c|c|c|}
\hline & Ethiopia & India & Nepal & Nigeria & South Africa & Uganda \\
\hline $\begin{array}{l}\text { Administrative health units in which Emerald was } \\
\text { implemented }\end{array}$ & Sodo & $\begin{array}{l}\text { Sehore } \\
\text { (Madhya } \\
\text { Pradesh) }\end{array}$ & Chitwan & Oshogbo & $\begin{array}{l}\text { Kenneth Kuanda } \\
\text { District (NW } \\
\text { Province) }\end{array}$ & Kamuli \\
\hline $\begin{array}{l}\text { Population of administrative health units } \\
\text { Country-level indicators }\end{array}$ & 165000 & 1311008 & 575058 & 288455 & 632790 & 740700 \\
\hline \multicolumn{7}{|l|}{ Economic and financial } \\
\hline World Bank resource category & Low & Lower-middle & Low & Lower-middle & Upper-middle & Low \\
\hline$\%$ Gross domestic product spent on health & 5.9 & 4.2 & 5.3 & 5.0 & 8.4 & 7.3 \\
\hline \% health budget spent on mental health & Not known & 0.06 & 0.17 & 0.40 & 4.50 & 0.44 \\
\hline \multicolumn{7}{|l|}{ Service availability (per 100 000) } \\
\hline Mental health out-patient facilities & 0.06 & 0.33 & 0.08 & 0.03 & 6.85 & 0.08 \\
\hline Psychiatric beds in general hospitals & 0.04 & 0.82 & 1.0 & 0.20 & 2.70 & 1.24 \\
\hline Beds in mental hospitals & 0.35 & 1.47 & 0.20 & 2.53 & 19.50 & 1.48 \\
\hline \multicolumn{7}{|l|}{ Human resources (per 100000 ) } \\
\hline Psychiatrists & 0.04 & 0.30 & 0.13 & 0.12 & 0.27 & 0.09 \\
\hline Nurses & 0.59 & 0.17 & 0.27 & 0.60 & 9.72 & 0.76 \\
\hline Psychologists & 0.02 & 0.05 & 0.02 & 0.02 & 0.31 & 0.02 \\
\hline \multicolumn{7}{|l|}{ Governance } \\
\hline $\begin{array}{l}\text { Mental health policy and/or legislation that is } \\
\text { up-to-date (i.e. updated in past } 10 \text { years) and } \\
\text { in accordance with international human rights }\end{array}$ & $\begin{array}{l}\text { Yes (policy) } \\
\text { No (legislation) }\end{array}$ & No & No & Yes & Yes & No \\
\hline \multicolumn{7}{|l|}{ Workforce capacity and training } \\
\hline $\begin{array}{l}\text { Most primary healthcare doctors had mental } \\
\text { health training in past } 5 \text { years }\end{array}$ & No & No & No & No & Not known & Yes \\
\hline $\begin{array}{l}\text { Primary care nurses can independently } \\
\text { diagnose and treat mental disorders }\end{array}$ & No & No & No & Yes & No & Yes \\
\hline \multicolumn{7}{|l|}{ Information systems } \\
\hline $\begin{array}{l}\text { Data on number of out-patients with mental } \\
\text { disorders }\end{array}$ & Not known & No & Yes & No & No & Yes \\
\hline $\begin{array}{l}\text { Data on number of people with mental disorders } \\
\text { treated in primary healthcare }\end{array}$ & Yes & No & No & No & Yes & Yes \\
\hline
\end{tabular}


or of poor quality in LMICs. Paper five in this series led by Mark Jordans and Oye Gureje describes the practical utility of new mental health system indicators developed by the Emerald team, ${ }^{37}$ and paper six led by Shalini Ahuja ${ }^{38}$ sets out our findings of how such indicators can best be implemented. ${ }^{39,40}$

\section{Recommendations paper}

Although the evidence generated by programmes such as Emerald can make original contributions to the scientific literature, more important is whether such information is actionable, namely can be communicated to those who are in a position to practically apply this information to improve treatment and care. José Luis Ayuso-Mateos and colleagues set out in paper seven what has been learned within Emerald on how to successfully achieve such forms of knowledge transfer. ${ }^{41}$

In our conclusion, paper eight presents a series of recommendations by the Emerald team for the strengthening of mental health systems in LMICs, taking a cross-cutting approach over the five different work packages that were implemented during the programme. $^{42}$

\section{Conclusions}

The field of global mental health is now undergoing a remarkable transformation with a long overdue appreciation of the scale of the contribution of mental disorders to the global burden of disease, ${ }^{8,43}$ and the potential for greater community cohesion and workplace productivity if people with these conditions are properly treated and supported. The inclusion of clear mental-health-related targets and indicators within the United Nations Sustainable Development Goals ${ }^{44-46}$ now intensifies the need for strong evidence about both how to provide effective treatments, and how to deliver these treatments within robust health systems.

Graham Thornicroft, Professor of Community Psychiatry, Centre for Global Menta Health and Centre for Implementation Science, Institute of Psychiatry, Psychology and Neuroscience, King's College London, UK; Maya Semrau, Research Fellow in Implementation Research, Centre for Global Health Research, Brighton and Sussex Medical School; and Centre for Global Mental Health, Institute of Psychiatry, Psychology and Neuroscience, King's College London, UK

Correspondence: Graham Thornicroft, David Goldberg Centre, Institute of Psychiatry, Psychology and Neuroscience, King's College London, De Crespigny Park, London SE5 8AF, UK. Email: graham.thornicroft@kcl.ac.uk

First received 28 Aug 2018, final revision 30 Jan 2019, accepted 30 Jan 2019

\section{Funding}

The research leading to these results was funded by the European Union's Seventh Framework Programme (FP7/2007-2013) under grant agreement number 305968. The funder had no role in study design, data collection and analysis, decision to publish or preparation of the manuscript. G.T. is supported by the National Institute for Health Research (NIHR) Collaboration for G.T. is supported by the National Institute for Health Research (NIHR) Collaboration for
Leadership in Applied Health Research and Care (CLAHRC) South London and by the NIHR Applied Research Centre (ARC) at King's College London NHS Foundation Trust, and the NIHR Applied Research and the NIHR Asset Global Health Unit award. The views expressed are those of the author(s) and not necessarily those of the NHS, the NIHR or the Department of Health and Social Care. G.T. receives support from the National Institute of Mental Health of the National Institutes of Health under award number R01MH100470 (Cobalt study). G.T. is supported by the UK Medical Research Council in relation the Emilia (MR/S001255/1) and Indigo Partnership (MR/R023697/1) awards. M.S. is supported by the NIHR Global Health Research Unit for Neglected Tropical Diseases at the Brighton and Sussex Medical School.

\section{Acknowledgements}

The partner organisations involved in Emerald were Addis Ababa University (AAU), Ethiopia: Butabika National Mental Hospital (BNH), Uganda; ARTTIC Germany; HealthNet TPO Netherlands; King's College London (KCL), UK; Public Health Foundation of India (PHFI), India; Transcultural Psychosocial Organization Nepal (TPO Nepal), Nepal; Universidad Autonoma de Madrid (UAM), Spain; University of Cape Town (UCT), South Africa; University of Ibadan (UI), Nigeria; University of KwaZulu-Natal (UKZN), South Africa; and World Health Organization (WHO), switzerland.
The Emerald programme was led by Professor Graham Thornicroft at KCL. The project coordination group consisted of Professor Atalay Alem (AAU), Professor José Luis AyusoMateos (UAM), Dr Dan Chisholm (WHO), Dr Stefanie Fülöp (ARTIC), Professor Oye Gureje (UI), Dr Charlotte Hanlon (AAU), Dr Mark Jordans (HealthNet TPO; TPO Nepal; KCL), Dr Fred Kigozi (BNH), Professor Crick Lund (UCT), Professor Inge Petersen (UKZN), Dr Rahul Shidhaye (PHFI) and Professor Graham Thornicroft (KCL).

Parts of the programme were also coordinated by Ms Shalini Ahuja (PHFI), Dr Jibril Omuya Abdulmalik (UI), Ms Kelly Davies (KCL), Ms Sumaiyah Docrat (UCT), Dr Catherine Egbe (UKZN), Dr Sara Evans-Lacko (KCL), Dr Margaret Heslin (KCL), Dr Dorothy Kizza (BNH), Ms Lola Kola (UI), Dr Heidi Lempp (KCL) Dr Pilar López (UAM). Ms Debra Marais (UKZN). Ms Blanca Mellor (UAM), Mr Durgadas Menon (PHFI), Dr James Mugisha (BNH), Ms Sharmishtha Nanda (PHFI), Dr Anita Patel $(\mathrm{KCL})$, Ms Shoba Raja (BasicNeeds, India; KCL), Dr Maya Semrau (KCL), Mr Joshua Ssebunya (BNH), Mr Yomi Taiwo (UI) and Mr Nawaraj Upadhaya (TPO Nepal).

The Emerald programme's scientific advisory board included A/Professor Susan Cleary (UCT), Dr Derege Kebede (WHO, Regional Office for Africa), Professor Harry Minas (University of Melbourne, Australia), Mr Patrick Onyango (TPO Uganda), Professor Jose Luis Salvador Carulla (University of Sydney, Australia), and Dr R Thara (Schizophrenia Research Foundation (SCARF), India).

The following individuals were members of the Emerald consortium: Dr Kazeem Adebayo (UI), MS Jennifer Agha (KCL), Ms Ainali Aikaterini (WHO), Dr Gunilla Backman (London School of Hygiene and Tropical Medicine; KCL), Mr Piet Barnard (UCT), Dr Harriet Birabwa (BNH), Ms Erica Breuer (UCT), Mr Shveta Budhraja (PHFI), Amit Chaturvedi (PHFI), Mr Daniel Chekol (AAU), Mr Naadir Daniels (UCT), Mr Bishwa Dunghana (TPO Nepal), Ms Gillian Hanslo (UCT), Ms Edith Kasinga (UCT), Ms Tasneem Kathree (UKZN), Mr Suraj Koirala (TPO Nepal), Professor Ivan Komproe (HealthNet TPO), Dr Mirja Koschorke (KCL), Mr Domenico Lalli (European Commission), Mr Nagendra Luitel (TPO Nepal), Dr David MCDaid (KCL), Ms Immaculate Nantongo (BNH), Dr Sheila Ndyanabangi (BNH), Dr Bibilola Oladeji (UI), Professor Vikram Patel (KCL), Ms Louise Pratt $(\mathrm{KCL})$, Professor Martin Prince (KCL), Ms M Miret (UAM), Ms Warda Sablay (UCT), Mr Bunmi Salako (UI), Dr Tatiana Taylor Salisbury (KCL), Dr Shekhar Saxena (WHO), Ms One Selohilwe (UKZN), Dr Ursula Stangel (GABO:mi), Professor Mark Tomlinson (UCT), Dr Abebaw Fekadu (AAU) and Ms Elaine Webb (KCL).

\section{Appendix}

\section{Masters-level teaching modules in health system strengthening developed by Emerald (Source: originally published in Semrau et al) ${ }^{1}$}

\begin{tabular}{|c|c|c|}
\hline $\begin{array}{l}\text { Module 1: Mental } \\
\text { health system } \\
\text { components }\end{array}$ & $\begin{array}{l}\text { Module } 2 \text { : Mental } \\
\text { health systems } \\
\text { research methods }\end{array}$ & $\begin{array}{l}\text { Module } 3 \text { : Mental health } \\
\text { system contexts - areas } \\
\text { of special attention }\end{array}$ \\
\hline $\begin{array}{l}1.1 \text { Introduction to } \\
\text { mental and } \\
\text { neurological } \\
\text { disorders }\end{array}$ & $\begin{array}{l}\text { 2.1 Mental health } \\
\text { epidemiology }\end{array}$ & $\begin{array}{l}\text { 3.1 Stigma and } \\
\text { discrimination }\end{array}$ \\
\hline $\begin{array}{l}1.2 \text { Health systems } \\
\text { concepts and } \\
\text { approaches }\end{array}$ & $\begin{array}{l}2.2 \text { Methods to } \\
\text { evaluate mental } \\
\text { health } \\
\text { interventions }\end{array}$ & $\begin{array}{l}\text { 3.2 Child and } \\
\text { adolescent mental } \\
\text { health }\end{array}$ \\
\hline $\begin{array}{l}\text { 1.3 Mental health } \\
\text { policy }\end{array}$ & $\begin{array}{r}2.3 \text { Economic } \\
\text { evaluation }\end{array}$ & 3.3 Older adults \\
\hline $\begin{array}{l}1.4 \text { Leadership and } \\
\text { governance }\end{array}$ & $\begin{array}{l}2.4 \text { Qualitative } \\
\text { research methods }\end{array}$ & 3.4 Suicidal behaviour \\
\hline $\begin{array}{l}1.5 \text { Service } \\
\text { organization }\end{array}$ & $\begin{array}{l}2.5 \text { Collaborative care } \\
\text { in mental health }\end{array}$ & $\begin{array}{l}\text { 3.5 Systems research in } \\
\text { humanitarian } \\
\text { settings }\end{array}$ \\
\hline $\begin{array}{l}\text { 1.6 Promotion and } \\
\text { prevention }\end{array}$ & $\begin{array}{l}\text { 2.6 Service user and } \\
\text { action research }\end{array}$ & $\begin{array}{l}\text { 3.6 Women/maternal/ } \\
\text { gender issues }\end{array}$ \\
\hline $\begin{array}{l}\text { 1.7 Health systems } \\
\text { financing }\end{array}$ & 2.7 Research ethics & $\begin{array}{l}\text { 3.7 Culture and mental } \\
\text { health }\end{array}$ \\
\hline 1.8 Human resources & $\begin{array}{l}2.8 \text { Implementation } \\
\text { science }\end{array}$ & \\
\hline $\begin{array}{l}1.9 \text { Information } \\
\text { systems and } \\
\text { monitoring and } \\
\text { evaluation }\end{array}$ & $\begin{array}{l}2.9 \text { Knowledge } \\
\text { translation }\end{array}$ & \\
\hline $\begin{array}{l}\text { 1.10 Interventions and } \\
\text { technologies, } \\
\text { delivery systems } \\
\text { and essential } \\
\text { treatments }\end{array}$ & $\begin{array}{l}\text { 2.10 Survival skills for } \\
\text { researchers }\end{array}$ & \\
\hline $\begin{array}{l}\text { 1.11 Human rights/ } \\
\text { equity }\end{array}$ & & \\
\hline
\end{tabular}




\section{References}

1 Semrau M, Evans-Lacko S, Alem A, Ayuso-Mateos JL, Chisholm D, Gureje O, et al. Strengthening mental health systems in low- and middle-income countries: the Emerald programme. BMC Med 2015; 13: 79.

2 World Health Organization. Everybody's Business: Strengthening Health Systems to Improve Health Outcomes. World Health Organization, 2007.

3 Thornicroft G, Chatterji S, Evans-Lacko S, Gruber M, Sampson N, AguilarGaxiola S, et al. Undertreatment of people with major depressive disorder in 21 countries. Br J Psychiatry 2017; 210: 119-24.

4 Alonso J, Liu Z, Evans-Lacko S, Sadikova E, Sampson N, Chatterji S, et al. Treatment gap for anxiety disorders is global: results of the World Menta Health Surveys in 21 countries. Depress Anxiety 2018; 35: 195-208.

5 Degenhardt L, Glantz M, Evans-Lacko S, Sadikova E, Sampson N, Thornicroft G, et al. Estimating treatment coverage for people with substance use disorders: an analysis of data from the World Mental Health Surveys. World Psychiatry 2017; 16: 299-307.

6 Wang PS, Aguilar-Gaxiola S, Alonso J, Angermeyer MC, Borges G, Bromet EJ, et al. Use of mental health services for anxiety, mood, and substance disorders in 17 countries in the WHO world mental health surveys. Lancet 2007: 370 841-50.

7 Whiteford HA, Ferrari AJ, Degenhardt L, Feigin V, Vos T. The global burden of mental, neurological and substance use disorders: an analysis from the global burden of disease study 2010. PLOS One 2015; 10: e0116820.

8 Vigo D, Thornicroft G, Atun R. Estimating the true global burden of mental illness. Lancet Psychiatry 2016; 3: 171-8.

9 Patel V, Saxena S, Frankish H, Boyce N. Sustainable development and global mental health - a Lancet Commission. Lancet 2016; 387: 1143-5.

10 Patel V, Saxena S, Lund C, Thornicroft G, Baingana F, Bolton P, et al. The Lancet Commission on global mental health and sustainable development. Lancet 2018: 392: 1553-98.

11 World Health Organization. mhGAP Intervention Guide for Mental, Neurological and Substance Use Disorders in Non-Specialized Health Settings: Mental Health Gap Action Programme (mhGAP) (version 2.0). World Health Organization, 2016.

12 Keynejad RC, Dua T, Barbui C, Thornicroft G. WHO Mental Health Gap Action Programme (mhGAP) Intervention Guide: a systematic review of evidence from low and middle-income countries. Evid Based Ment Health 2018; 21: 30-4.

13 Patel V, Chisholm D, Parikh R, Charlson FJ, Degenhardt L, Dua T, et al. Addressing the burden of mental, neurological, and substance use disorders: key messages from Disease Control Priorities, 3rd edition. Lancet 2016; 387: 1672-85.

14 Petersen I, Evans-Lacko S, Semrau M, Barry M, Chisholm D, Gronholm P, et al. Population and community platform interventions. In Mental, Neurological, and Substance Use Disorders: Disease Control Priorities (3rd edn), Vol. 4 (eds V Patel, D Chisholm, T Dua, R Laxminarayan, ME Medina-Mora). World Bank, 2016.

15 Petersen I, Marais D, Abdulmalik J, Ahuja S, Alem A, Chisholm D, et al. Strengthening mental health system governance in six low- and middle-income countries in Africa and South Asia: challenges, needs and potential strategies. Health Policy Plan 2017; 32: 699-709.

16 World Health Organization. Mental Health Atlas. WHO, 2011.

17 World Health Organization and Ministry of Health. WHO-AIMS Report on Mental Health System in Nepal. WHO, 2006

18 Evans-Lacko S, Hanlon C, Alem A, Ayuso-Mateos J, Chisholm C, Gureje O, et al. Evaluation of capacity-building strategies for mental health system strengthening in low- and middle-income countries for service users and carers, policymakers and planners, and researchers. BJPsych Open 2019; this issue.

19 Thornicroft G, Cooper S, Van Bortel T, Kakuma R, Lund C. Capacity building in global mental health research. Harvard Rev Psychiatry 2012; 20: 13-24.

20 Semrau M, Lempp H, Keynejad R, Evans-Lacko S, Mugisha J, Raja S, et al. Service user and caregiver involvement in mental health system strengthening in lowand middle-income countries: systematic review. BMC Health Serv Res 2016: 16: 79

21 Hanlon C, Semrau M, Alem A, Abayneh S, Abdulmalik J, Docrat S, et at. Evaluating capacity-building for mental health system strengthening in lowand middle-income countries for service users and caregivers, service planners and researchers. Epidemiol Psychiatr Sci 2018; 27: 3-10.

22 Lempp H, Abayneh S, Gurung D, Kola L, Abdulmalik J, Evans-Lacko S, et al. Service user and caregiver involvement in mental health system strengthening in low- and middle-income countries: a cross-country qualitative study. Epidemiol Psychiatr Sci 2018; 27: 29-39.
23 Semrau M, Alem A, Abdulmalik J, Docrat S, Evans-Lacko S, Gureje O, et al. Developing capacity-building activities for mental health system strengthening in low- and middle-income countries for service users and caregivers, service planners, and researchers. Epidemiol Psychiatr Sci 2018;27: 11-21.

24 Thornicroft G, Semrau M. Mental health capacity building in low and middle income countries: the Emerald Programme. Epidemiol Psychiatr Sci 2018; 27 : $1-2$.

25 Gurung D, Upadhyaya N, Magar J, Giri NP, Hanlon C, Jordans MJD. Service user and care giver involvement in mental health system strengthening in Nepal: a qualitative study on barriers and facilitating factors. Int J Ment Health Syst 2017; 11: 30

26 Samudre S, Shidhaye R, Ahuja S, Nanda S, Khan A, Evans-Lacko S, et al. Service user involvement for mental health system strengthening in India: a qualitative study. BMC Psychiatry 2016; 16: 269.

27 Chisholm D, Docrat S, Abdulmalik J, Alem A, Gureje O, Gurung D, et al. Strategies for moving towards more equitable and sustainable mental health financing in low- and middle-income countries: findings from the Emerald project. BJPsych Open 2019; this issue.

28 Chisholm D, Burman-Roy S, Fekadu A, Kathree T, Kizza D, Luitel NP, et al Estimating the cost of implementing district mental healthcare plans in five low- and middle-income countries: the PRIME study. Br J Psychiatry 2016; 208 (suppl 56): s71-8.

29 Chisholm D, Sweeny K, Sheehan P, Rasmussen B, Smit F, Cuijpers P, et al. Scaling-up treatment of depression and anxiety: a global return on investment analysis. Lancet Psychiatry 2016; 3: 415-24.

30 Chisholm D, Heslin M, Docrat S, Nanda S, Shidhaye R, Upadhaya N, et al. Scaling-up services for psychosis, depression and epilepsy in sub-Saharan Africa and South Asia: development and application of a mental health systems planning tool (OneHealth). Epidemiol Psychiatr Sci 2017; 26: 234-44.

31 Petersen I, van Rensburg A, Kigozi F, Semrau M, Hanlon C, Fekadu A, et al. Scaling up integrated mental health in six low- and middle-income countries: obstacles, synergies and implications for systems reform. BJPsych Open 2019; this issue.

32 Marais DL, Petersen I. Health system governance to support integrated mental health care in South Africa: challenges and opportunities. Int J Ment Health Syst 2015; 9: 14.

33 Petersen I, Fairall L, Bhana A, Kathree T, Selohilwe O, Brooke-Sumner C, et al. Integrating mental health into chronic care in South Africa: the development of a district mental healthcare plan. Br J Psychiatry 2016; 208 (suppl 56): s29-39.

34 Petersen I, Evans-Lacko S, Semrau M, Barry MM, Chisholm D, Gronholm P, et al. Promotion, prevention and protection: interventions at the population- and community-levels for mental, neurological and substance use disorders in low- and middle-income countries. Int J Ment Health Syst 2016; 10: 30.

35 Mugisha J, Abdulmalik J, Hanlon C, Petersen I, Lund C, Upadhaya N, et al Health systems context (s) for integrating mental health into primary health care in six Emerald countries: a situation analysis. Int $J$ Mental Health Syst 2017; $11: 7$.

36 Upadhaya N, Jordans MJ, Pokhrel R, Gurung D, Adhikari RP, Petersen I, et al. Current situations and future directions for mental health system governance in Nepal: findings from a qualitative study. Int J Ment Health Syst 2017; 11: 37

37 Jordans $\mathrm{M}$, Chisholm D, Semrau M, Gurung D, Abdulmalik J, Ahuja S, et al. Evaluation of performance and perceived utility of mental health care indicators in routine health information systems in five low- and middle-income countries. BJPsych Open 2019; this issue.

38 Ahuja S, Hanlon C, Chisholm D, Semrau M, Gurung D, Abdulmalik J, et al. Experience of implementing new mental health indicators within information systems in six low- and middle-income countries: qualitative study. BJPsych Open; 2019; this issue.

39 Jordans MJ, Chisholm D, Semrau M, Upadhaya N, Abdulmalik J, Ahuja S, et al. Indicators for routine monitoring of effective mental healthcare coverage in low- and middle-income settings: a Delphi study. Health Policy Plan 2016; 31 : 1100-6.

40 Upadhaya N, Jordans MJ, Abdulmalik J, Ahuja S, Alem A, Hanlon C, et al. Information systems for mental health in six low and middle income countries: cross country situation analysis. Int J Ment Health Syst 2016; 10: 60.

41 Ayuso-Mateos J, Miret M, Lopez-Garcia P, Alem A, Chisholm D, Gureje O, et al. Effective methods for knowledge transfer to strengthen mental health systems in low- and middle-income countries. BJPsych Open 2019; this issue.

42 Semrau M, Alem A, Ayuso-Mateos JL, Chisholm C, Gureje O, Hanlon C, et al. Strengthening mental health systems in low- and middle-income countries: recommendations from the Emerald programme. BJPsych Open 2019; this issue. 
43 Whiteford HA, Degenhardt L, Rehm J, Baxter AJ, Ferrari AJ, Erskine HE, et al. Global burden of disease attributable to mental and substance use disorders: findings from the Global Burden of Disease Study 2010. Lancet. 2013; 382 1575-86.

44 United Nations. The 2030 Agenda for Global Action and the Sustainable Development Goals. UN, 2015.
45 Gureje 0, Thornicroft G. Health equity and mental health in post-2015 sustainable development goals. Lancet Psychiatry 2015; 2: 12-4.

46 Thornicroft G, Votruba N. Does the United Nations care about mental health? Lancet Psychiatry 2016; 3: 599-600. 